Special issue of the International Conference on Computational and Experimental Science and Engineering (ICCESEN 2014)

\title{
Stable Light Level Detection in the Light Pools Using Neural Network Algorithms
}

\author{
İ.S. ÜNCت̈̈ ${ }^{a *}$, A. ARISOY ${ }^{b}$, B. BÜYÜKARIKAN ${ }^{b}$ \\ ${ }^{a}$ Süleyman Demirel University, Technology Faculty, Electrical and Electronic Engineering Department, \\ Isparta, Turkey \\ ${ }^{b}$ Selçuk Demirel University Sarayönü Vacational School, Computer Technology Department, Konya, Turkey \\ One of the requirements in machine vision applications is that the light source and the environment are selected \\ correctly. If the analyzed object is not properly illuminated, it is inadequate for obtaining the desired result using \\ the captured images. A correct lighting luminaire allows to distinguish the examined object from the environment \\ it interacts with and ensures that its attributes are obtained correctly. In this study an intelligent dynamic lighting \\ system for illumination of a closed area has been developed. The tested luminaire has three arms. Accelerometer \\ readings are used for positioning and orientation. Using the developed system, the positions of the armature can be \\ estimated by bipolar sigmoid technique, according to the point the user wants to illuminate. The system measures \\ the light level with $72 \mathrm{LDR}$, calibrated with a luxmetre.
}

DOI: 10.12693/APhysPolA.128.B-474

PACS: 88.05.Tg, 07.05.Mh

\section{Introduction}

Lighting, as defined by CIE, is the application of light to see the environment and objects properly [1]. The first step to get an image of an objects in better quality, is to use a good lighting system [2]. A good lighting system provides enhanced resolving power in optical systems and better results from the output data [3]. A controlled system enables one to distinguish objects from their environment, and to emphasize the properties of the surfaces of interest [4].

The purpose of the lighting is to use the armature in order to respond to the requests. Variety of properties of a variety of places narrow the choice of the lamps and the armatures. Thus, in accordance with varying conditions and special circumstances, the change of lighting level in different spots is required [5].

In this study, the changes of light levels in the area

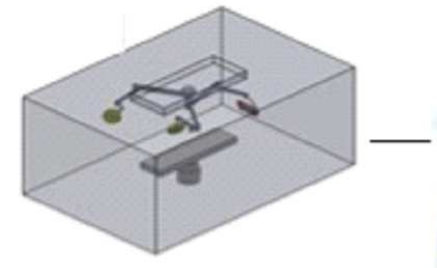

Lighting Pool's

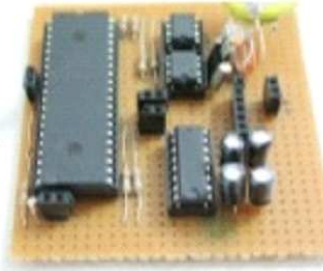

The Control Board of the light pool, which are requested to be illuminated, were followed by a dynamic armature, controlled by a trained artificial neural network. Illumination inside the light pool was measured using light sensors, calibrated with a luxmeter. Data from the sensors was collected by the software with the aid of serial port electronic data acquisition card. The accuracy tables of the system have been calculated using image processing techniques.

\section{Stable light level detection in the light pool}

Quality of lighting determines quantitatively the degree of lighting sufficiency [6]. Having a sufficiently lighted environment is required for a good implementation of image processing in the working area. Controlled lighting conditions, which are constant, as much as possible, provide an increase in imaging performance [7]. Lighting design is shown in Fig. 1.

Fig. 1. Lighting design.

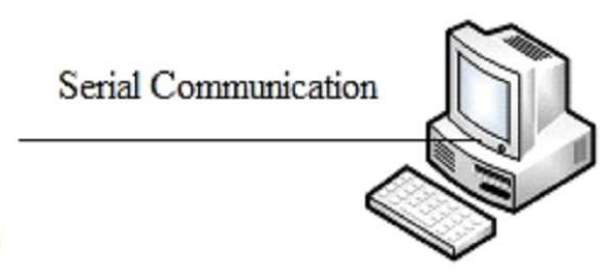

The User and Evaluating Interface

*corresponding author; e-mail: serkanuncu@sdu.edu.tr 
Light sensors are used to measure quantity of incoming light. These sensors determine the necessity of increasing or decreasing the light outputs of LED armature lights [8]. The quantity of light falling on the unit of surface has been calculated with LDR (light dependent resistors) placed under the light pool. In order to measure the light falling on the area, LDRs have been placed on the $70 \times 140 \mathrm{~cm}^{2}$ platform, as seen in Fig. 2 .

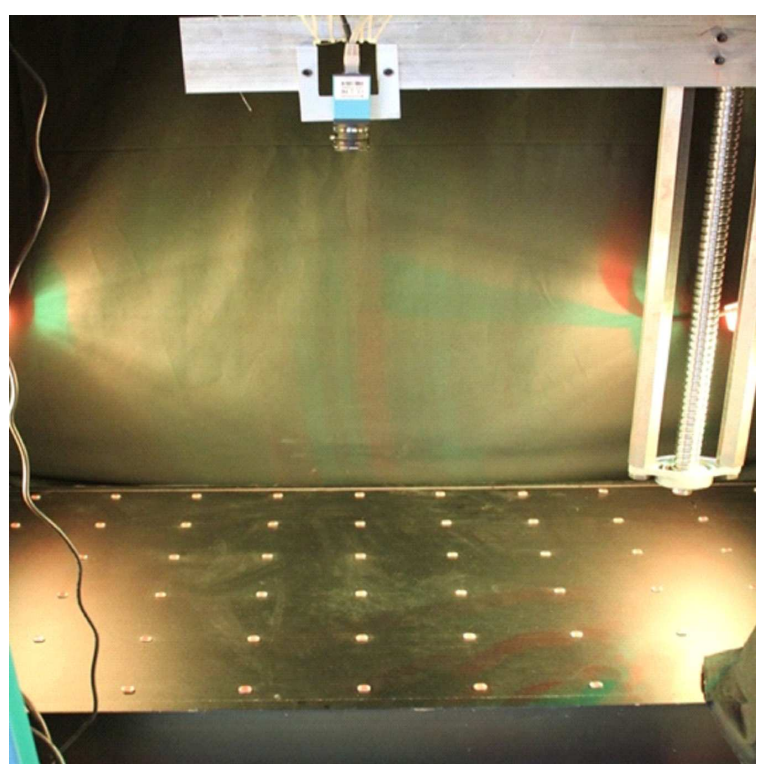

Fig. 2. View of the platform inside the light pool.

The level of the light, falling on the platform, is provided by a control circuit shown in Fig. 3. This circuit consists of BC547 transistors, integrated microcontrollers and necessary supporting elements used for measurement and serial communication.

The starting point lighting fixture has three units in each arm (Fig. 4). These points are marked with $60^{\circ}$ angle and the angle values are taken into account during the measurement.

For the calculation of the arm angles, an artificial neural network is used with 72 inputs (LDR data) and 9 outputs. Bipolar sigmoid activation functions of nerve cells and back propagation neural network learning algorithm were used for training. The accuracy of lighting in the desired area was determined by taking a photo of the platform and then by converting it to gray-scale using image processing techniques.

\section{Conclusions}

Because it is not possible to achieve a good lighting by placing the lighting fixtures randomly, the analysis and advanced calculation methods are needed. As a result of the comparison of the developed system's output with the manual measurements, a $99.1 \%$ accuracy rate was achieved. Depending on the shooting angle of the camera, differences may occur between the location which is

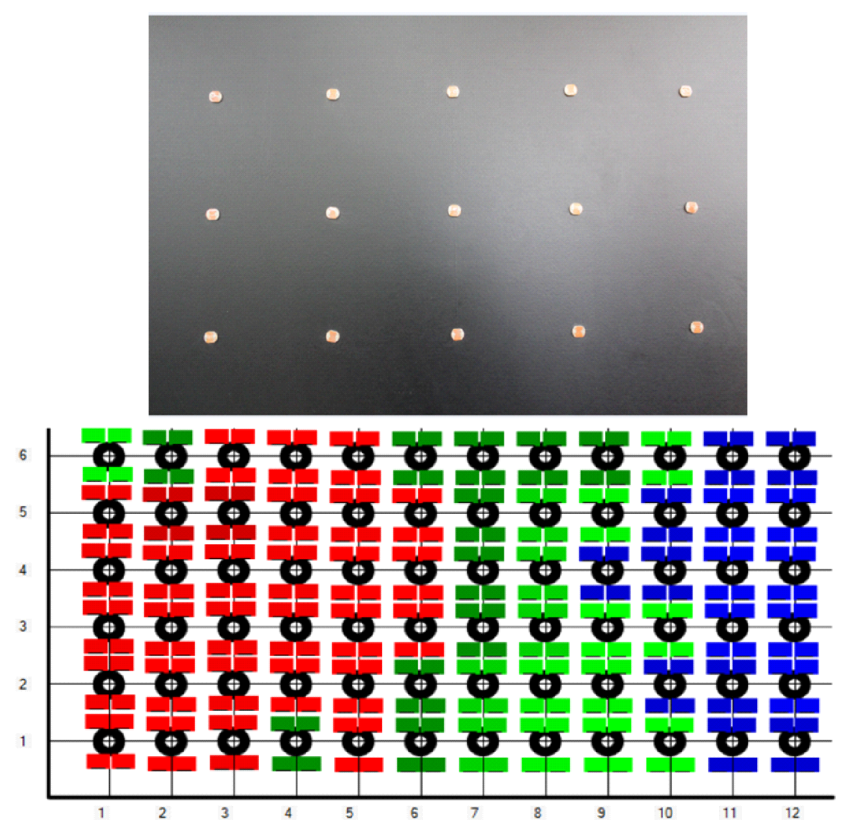

Fig. 3. Control circuit and platform.
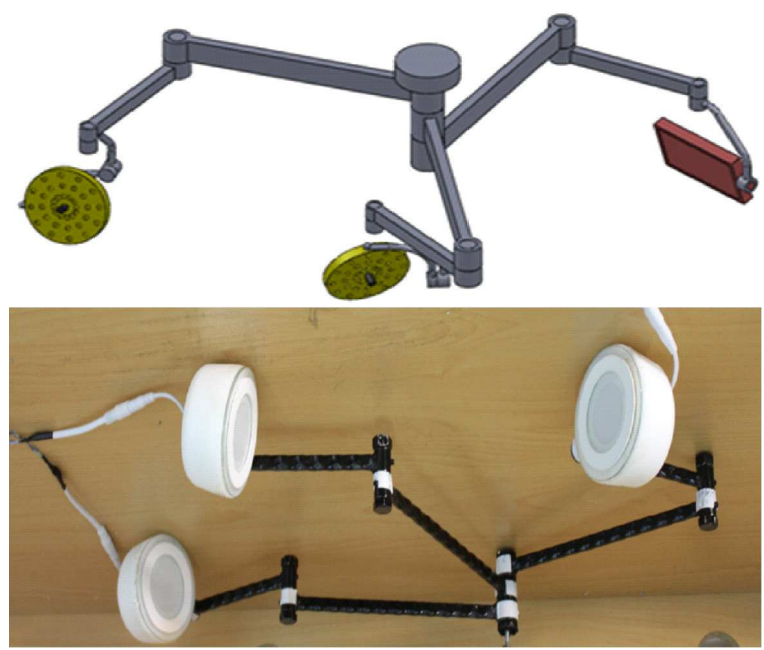

Fig. 4. Lighting fixtures and arms.

intended to be illuminated and the area from which the camera captures the light. By taking this into account, the precision of comparison was found to be $99 \%$.

\section{Acknowledgments}

Authors thank TÜBİTAK for financial support of the project number 113E291.

\section{References}

[1] M.S. Rea, The IESNA Lighting handbook: Reference G3 Application, 9th ed., IESNA, Illuminating Engineering Society Press, New York 2000.

[2] J. Mitéran, P. Geveaux, R. Bailly, P. Gorria, Industrial Electronics, 7-11 July (1997). 
[3] Zou Huadong, Zhu Liangrong, Tan Ming, 2009 Asia Pacific Conference on Postgraduate Research in $\mathrm{Mi}$ croelectronics 83 Electronics (PrimeAsia), Shanghai 2009, p. 392.

[4] A. Hornberg, Handbook of Machine Vision, 1st ed., Wiley-VCH, Weinheim 2008.

[5] A. Arısoy,, M.Sc. Thesis, Süleyman Demirel University Graduate School of Applied and Natural Sciences, Isparta 2013.

[6] M.Ş. Sözen, II. Ulusal Aydınlatma Sempozyumu, Diyarbakır 2003, p. 1.
[7] B. Büyükarıkan, M.Sc. Thesis, Süleyman Demirel University Graduate School of Applied and Natural Sciences, Isparta 2014.

[8] A.W. Louw, C. Neethling, Proc. 21st Domestic Use of Energy Conference (DUE), Cape Town 2013. 